\title{
Delaying the oocyte maturation trigger by one day leads to a higher metaphase II oocyte yield in IVF/ICSI: a randomised controlled trial
}

Frank Vandekerckhove ${ }^{1 *}$, Jan Gerris ${ }^{1}$, Stijn Vansteelandt ${ }^{2}$, An De Baerdemaeker ${ }^{1}$, Kelly Tilleman ${ }^{1}$ and Petra De Sutter ${ }^{1}$

\begin{abstract}
Background: The negative impact of rising progesterone levels on pregnancy rates is well known, but data on mature oocyte yield are conflicting. We examined whether delaying the oocyte maturation trigger in IVF/ICSI affected the number of mature oocytes and investigated the potential influence of serum progesterone levels in this process.

Methods: Between January 31, 2011, and December 31, 2011, 262 consecutive patients were monitored using ultrasound plus hormonal evaluation. Those with $>=3$ follicles with a mean diameter of $>=18 \mathrm{~mm}$ were divided into 2 groups depending on their serum progesterone levels. In cases with a progesterone level $<=1 \mathrm{ng} / \mathrm{ml}$, which was observed in 59 patients, 30-50\% of their total number of follicles (only counting those larger than $10 \mathrm{~mm}$ ) were at least $18 \mathrm{~mm}$ in diameter. These patients were randomised into 2 groups: in one group, final oocyte maturation was triggered the same day; for the other, maturation was triggered 24 hours later. Seventy-two patients with progesterone levels $>1 \mathrm{ng} / \mathrm{ml}$ were randomised in the same manner, irrespective of the percentage of larger follicles $(>=18 \mathrm{~mm}$ ). The number of metaphase II oocytes was our primary outcome variable. Because some patients were included more than once, correction for duplicate patients was performed.

Results: In the study arm with low progesterone $(<=1 \mathrm{ng} / \mathrm{ml})$, the mean number of metaphase II oocytes (+/-SD) was $10.29(+/-6.35)$ in the group with delayed administration of the oocyte maturation trigger versus $7.64(+/-3.26)$ in the control group. After adjusting for age, the mean difference was 2.41 (95\% Cl: $0.22-4.61 ; p=0.031$ ). In the study arm with elevated progesterone $(>1 \mathrm{ng} / \mathrm{ml})$, the mean numbers of metaphase II oocytes $(+/-S D)$ were 11.81 $(+/-9.91)$ and 12.03 (+/-7.09) for the delayed and control groups, respectively. After adjusting for PCOS (polycystic ovary syndrome) and female pathology, the mean difference was $-0.44(95 \% \mathrm{Cl}:-3.65-2.78 ; \mathrm{p}=0.79)$.
\end{abstract}

Conclusions: Delaying oocyte maturation in patients with low progesterone levels yields greater numbers of mature oocytes.

Trial registration: B67020108975 (Belgian registration) and NCT01980563 (ClinicalTrials.gov).

\footnotetext{
* Correspondence: vandekerckhove@gmail.com

${ }^{1}$ Centre for Reproductive Medicine, University Hospital Ghent, De Pintelaan

185, Gent 9000, Belgium

Full list of author information is available at the end of the article
}

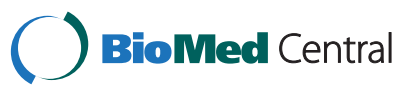

(C) 2014 Vandekerckhove et al.; licensee BioMed Central Ltd. This is an Open Access article distributed under the terms of the Creative Commons Attribution License (http://creativecommons.org/licenses/by/2.0), which permits unrestricted use,

distribution, and reproduction in any medium, provided the original work is properly credited. The Creative Commons Public Domain Dedication waiver (http://creativecommons.org/publicdomain/zero/1.0/) applies to the data made available in this article, unless otherwise stated. 


\section{Background}

Various ultrasound and hormonal criteria have been used to determine the moment to trigger oocyte maturation in IVF/ICSI cycles. Historically, the moment for triggering oocyte maturation has been based on follicle diameters that were measured using ultrasound and levels of serum estradiol [1,2]. A Cochrane review [3] stated that the use of sonographic criteria alone might be sufficient but that the simultaneous determination of serum estradiol is still recommended as long as large randomised controlled trials have not shown that the incidence of ovarian hyperstimulation syndrome is equal in both groups. Combined monitoring was recommended as "a precautionary good practice point". These findings were mainly gathered in agonist protocols.

The decision to advance trigger oocyte maturation by 24 hours did not seem to have a positive effect on the probability of pregnancy in an antagonist protocol [4].

Irrespective of the use of an agonist or an antagonist for suppression, we tested whether the protocol of Garcia-Velasco et al. [5], in which oocyte maturation is triggered as soon as 3 follicles reach diameters of $18 \mathrm{~mm}$, could be adapted further. These authors used it to compare ovarian steroid production when either an agonist or an antagonist was used. We also applied a uniform protocol for monitoring and hypothesised that delaying the administration of the trigger for 24 hours would result in a higher yield of mature oocytes, which served as our primary outcome variable. To evaluate whether this modification had any consequences on pregnancy rates or pregnancy outcomes, these variables were further evaluated as secondary outcomes. This randomised controlled trial was performed in patients with normal serum progesterone levels.

It is known that high progesterone levels $(>1.5 \mathrm{ng} / \mathrm{ml})$ have a deleterious effect on the endometrium and, thus, on pregnancy rates [6]. When progesterone levels are slightly elevated ( $>1 \mathrm{ng} / \mathrm{ml}$ ), it can be difficult to decide whether to continue the stimulation procedure for one more day. A randomised controlled trial was carried out on this group of patients to evaluate the number of mature oocytes at retrieval as the primary outcome variable. Pregnancy rates and outcomes were important secondary variables.

\section{Methods}

This study was approved by the Ethical Committee of the Ghent University Hospital (B67020108975) and as a clinical trial internationally (NCT01980563 at ClinicalTrials.gov). It was part of a larger prospective trial in a single university hospital (Gent, Belgium) that compared cycle monitoring for IVF/ICSI in two parallel control groups: those with ultrasound monitoring versus those with combined monitoring (ultrasound plus hormonal monitoring). Between January 31, 2011, and December 31, 2011, 262 consecutive patients from the latter group were eligible for the present trial.

Inclusion criteria were the presence of both ovaries and being a female less than 45 years of age. Patients with ovarian cysts at the start of the ovarian stimulation procedure were excluded. Ovarian reserve was determined by measuring anti-Müllerian hormone $(\mathrm{AMH})$ before starting treatment (Immunotech, Beckman Coulter Company, Brea, CA, USA).

Various protocols for controlled ovarian hyperstimulation were applied. Either recombinant FSH (Gonal F ${ }^{\ominus}$, Merck Serono, Geneva, Switzerland) or urinary FSH (Menopur ${ }^{\circ}$, Ferring Pharmaceuticals, Saint-Prex, Switzerland) was used with daily doses between 150 and $300 \mathrm{U}$, dependent on age, anti-Müllerian hormone (AMH) levels and previous response, if applicable. In the agonist group, $0.1 \mathrm{mg}$ triptorelin (Decapeptyl ${ }^{\oplus}$, Ipsen, Paris, France) was administered subcutaneously for 7 days starting on cycle day 1 , and gonadotrophins were started on cycle day 3 . In the antagonist group, a fixed protocol was used: gonadotrophins were started on cycle day 3, and $0.25 \mathrm{mg}$ cetrorelix (Cetrotide ${ }^{\circ}$, Merck Serono, Geneva, Switzerland) was injected subcutaneously as a daily dose from the 6th day of stimulation until the day of oocyte maturation triggering. After 1 week of stimulation with gonadotrophins, a first ultrasound monitoring session was planned. Serum levels of estradiol, LH and progesterone were determined simultaneously. All samples were analysed with ECLIA (Modular E170, Roche, Vilvoorde, Belgium). The inter- and intra-assay coefficients of variability for the progesterone assay were $3.46-6.71 \%$ and $1.1-7.0 \%$, respectively. The cut-off for the sensitivity of the test (minimal detectable level) was $0.15 \mathrm{ng} / \mathrm{ml}$. Depending on the findings, patients were scheduled for additional monitoring every 1 or 2 days. As soon as three follicles reached a diameter of at least $18 \mathrm{~mm}$, patients were divided into two groups: those with serum progesterone $>1 \mathrm{ng} / \mathrm{ml}$ and those with a low progesterone level, defined as $\leq 1 \mathrm{ng} /$ $\mathrm{ml}$. The results of the individual monitoring of the patients were centralised and discussed at a daily staff meeting. All 6 staff members who were performing monitoring enrolled patients equally.

When the serum progesterone level was $>1 \mathrm{ng} / \mathrm{ml}$, patients were randomised (single blinded). They received 5000 $\mathrm{U}$ of human chorionic gonadotrophin (hCG) (Pregnyl ${ }^{\circ}$, Merck Sharp \& Dohme, NJ, USA) on the same day (high progesterone early [HPE] group) or 24 hours later (high progesterone late [HPL] group). A computer-generated list was used, and allocation concealment was performed by a secretary over the telephone. This procedure was supervised by a single observer (FV). No further monitoring was planned the day after randomisation into the HPL group. When more than 3 oocytes were expected, oocytes were retrieved with a single lumen needle. Flushing through 
a double lumen needle was performed in all other cases. All laboratory procedures were carried out as previously described [7]. In cases of ICSI treatment, the number of mature oocytes was dependent on their morphological appearance after denudation. In IVF cycles, all oocytes that were inseminated were classified as mature, as is acceptable convention per the literature. A maximum of 2 embryos were transferred 3 days after oocyte retrieval. Luteal support consisted of $600 \mathrm{mg}$ micronised progesterone (Utrogestan', Besins Healthcare, Bangkok, Thailand) that was administered vaginally in three daily doses, starting after oocyte collection, and continued until 2 weeks after transfer if not pregnant or until a clinical pregnancy was confirmed by ultrasound.

For patients with a low progesterone level $(<1 \mathrm{ng} / \mathrm{ml})$, a different approach was used. When $>50 \%$ of the follicles were larger than $18 \mathrm{~mm}, 5000 \mathrm{U}$ of hCG was injected on the same day. Only follicles of at least $10 \mathrm{~mm}$ were counted to obtain this ratio. If the number of follicles with a diameter of at least $18 \mathrm{~mm}$ was between 30 and $50 \%$ of the total number counted, the patient was randomised. They received $5000 \mathrm{U}$ of hCG on the same day (low progesterone early [LPE] group) or 24 hours later (low progesterone late [LPL] group), and no extra monitoring procedure was performed the day after randomisation in the LPL group. Allocation was performed as previously described. Further treatment was completed as described above for patients with a progesterone level $>1 \mathrm{ng} / \mathrm{ml}$.
The results of the trial were processed anonymously by a single observer (FV). The number of metaphase II oocytes (MII) was our primary outcome variable. Secondary variables that demonstrate the oocyte yield were the number of oocytes retrieved, the number of fertilised oocytes (2PN) and the number of good quality embryos (GQE) on day 3. Other secondary outcome variables were defined according to the literature [8]: pregnancy rates $(\mathrm{PR})$, clinical pregnancy rates (CPR), ongoing pregnancy rates (OPR) and live birth rates (LBR) as expressed per cycle; clinical implantation ratios (CIR/E), ongoing implantation ratios (OIR/E) and live birth ratios (LBR/E) were calculated for each individual embryo that was transferred.

The sample size calculation for the group with progesterone levels $\leq 1 \mathrm{ng} / \mathrm{ml}$ was based on a mean yield of 6 mature oocytes $(\mathrm{SD}=3)$ in the LPE group versus 11 $(\mathrm{SD}=6)$ in the LPL group $[4,9]$, resulting in a required sample size of 15 in each group (Welch's t-test, 5\% significance level, $80 \%$ power). For patients with high progesterone levels $(>1 \mathrm{ng} / \mathrm{ml})$, we found no comparable data in the literature as a reference. We therefore decided to include patients in the HPE and HPL groups concomitantly with the LPE and LPL groups.

The descriptive analyses in Table 1 were based on Fisher's exact tests for proportions and Student's t-tests for continuous outcomes; when the data were skewed or contained outliers, the non-parametric Mann-Whitney

Table 1 Descriptive statistics

\begin{tabular}{|c|c|c|c|c|}
\hline Variable & $\begin{array}{c}\text { Prog } \leq 1 \mathrm{ng} / \mathrm{ml} \\
\text { hCG day } 0 \text { (LPE) }\end{array}$ & $\begin{array}{c}\text { Prog } \leq 1 \mathrm{ng} / \mathrm{ml} \\
\text { hCG day +1 (LPL) }\end{array}$ & $\begin{array}{c}\text { Prog }>1 \text { ng/ml } \\
\text { hCG day } 0 \text { (HPE) }\end{array}$ & $\begin{array}{c}\text { Prog }>1 \mathrm{ng} / \mathrm{ml} \\
\text { hCG day }+1 \text { (HPL) }\end{array}$ \\
\hline Number of patients [cycles] & $20[28]$ & $31[31]$ & $28[36]$ & $25[36]$ \\
\hline Age (years) & $34.5(4.4)$ & $33.5(4.9)$ & $30.5(3.8)$ & $31.9(4.2)$ \\
\hline Gravidity & $0.9(1.3)$ & $0.9(1.7)$ & $0.5(0.9)$ & $0.8(1.4)$ \\
\hline Parity & $0.4(0.6)$ & $0.4(0.8)$ & $0.3(0.6)$ & $0.3(0.9)$ \\
\hline Duration of infertility (years) & $3.3(2.1)$ & $4.3(1.4)$ & $4.3(1.9)$ & $5.2(2.9)$ \\
\hline$A M H(n g / m l)^{*}$ & $2.7(2.1-5.0)$ & $4.1(2.5-6.2)$ & $4.6(3.2-5.7)$ & $3.0(2.3-5.2)$ \\
\hline$E 2(p g / m l)^{*}$ & $1460(956-2150)$ & $1390(964-2110)$ & $1298(810-1825)$ & 1130 (866-1978) \\
\hline Progesteron $(\mathrm{ng} / \mathrm{m} /)^{*}$ & $0.7(0.5-0.9)$ & $0.8(0.5-0.9)$ & $1.5(1.2-1.8)$ & $1.4(1.2-1.6)$ \\
\hline Number of embryos transferred & $1.25(0.64)$ & $1.52(0.72)$ & $1.29(0.60)$ & $1.28(0.46)$ \\
\hline Female pathology & $6 / 20$ & $10 / 31$ & $16 / 28$ & $9 / 25$ \\
\hline Endometriosis & $4 / 20$ & $2 / 31$ & $7 / 28$ & $0 / 25$ \\
\hline Ovarian dysfunction & $0 / 20$ & $2 / 31$ & $3 / 28$ & $1 / 25$ \\
\hline PCOS & $0 / 20$ & $1 / 31$ & $0 / 28$ & $2 / 25$ \\
\hline Male pathology & $7 / 20$ & $12 / 31$ & $13 / 28$ & $14 / 25$ \\
\hline Antagonist & $17 / 28$ & $15 / 31$ & $17 / 36$ & $19 / 36$ \\
\hline Recombinant FSH & $20 / 28$ & $24 / 31$ & $28 / 36$ & $34 / 36$ \\
\hline Experienced performer transfer & $20 / 28$ & $19 / 31$ & $22 / 36$ & $22 / 36$ \\
\hline
\end{tabular}

Numbers are expressed as numbers or as means (SD) unless explained differently. *Numbers are expressed as median (first and third quartile). $p>0.05$ for all variables. 
Patients with $30-50 \%$ of follicles $\geq 18 \mathrm{~mm}$ and serum progesterone $\leq 1 \mathrm{ng} / \mathrm{ml}$

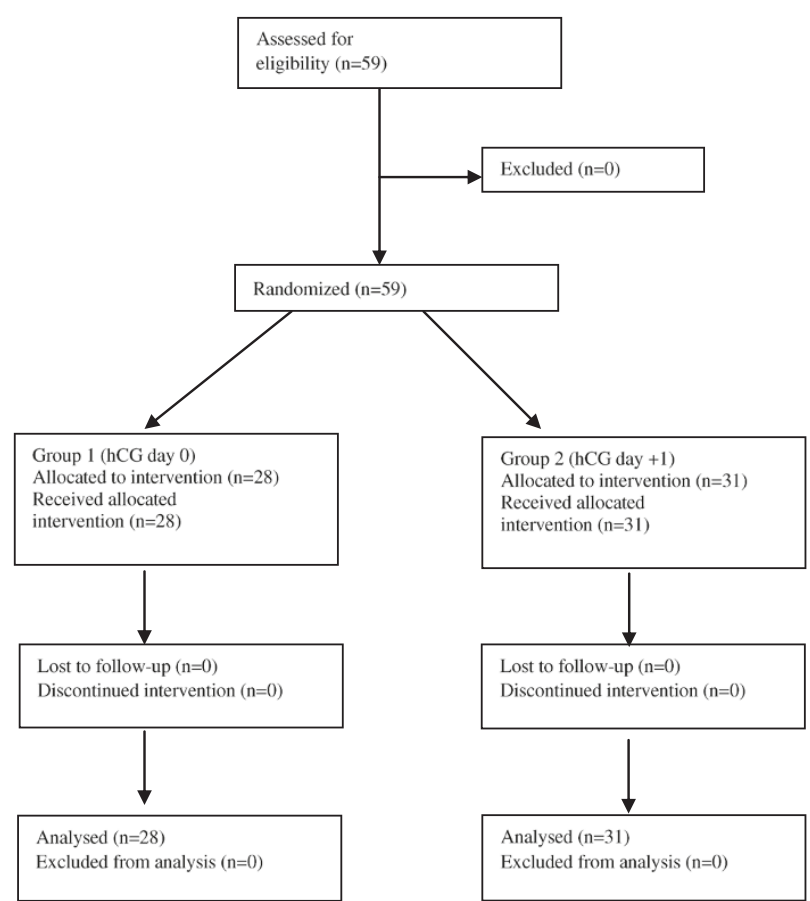

Patients with serum progesterone $>1 \mathrm{ng} / \mathrm{ml}$

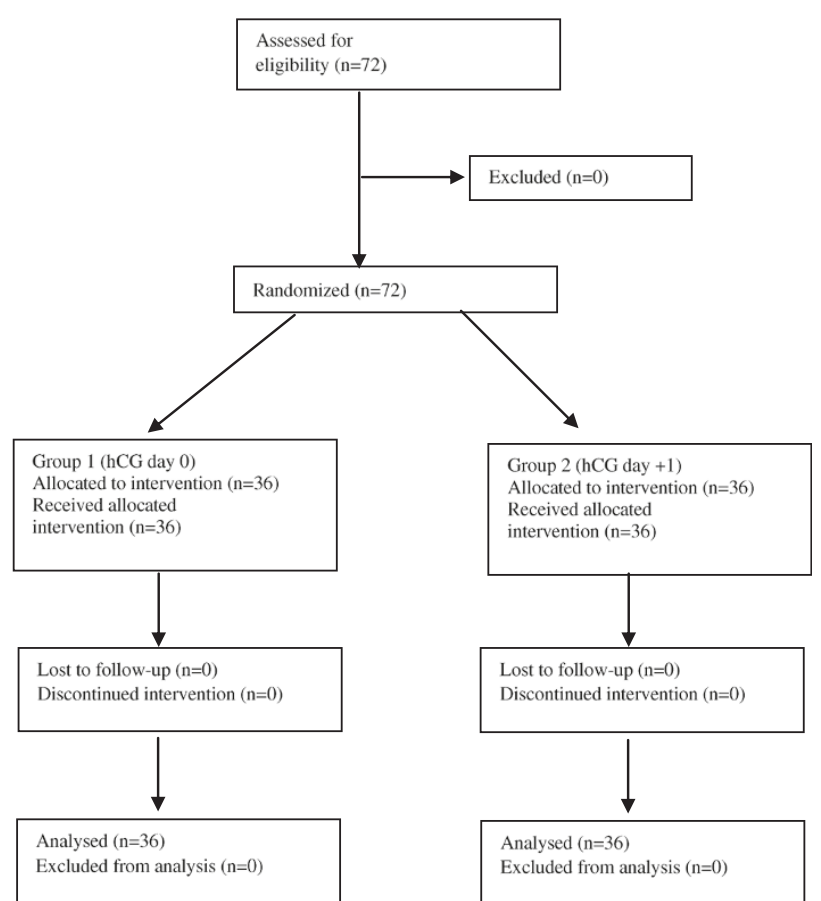

Figure 1 CONSORT flow chart.

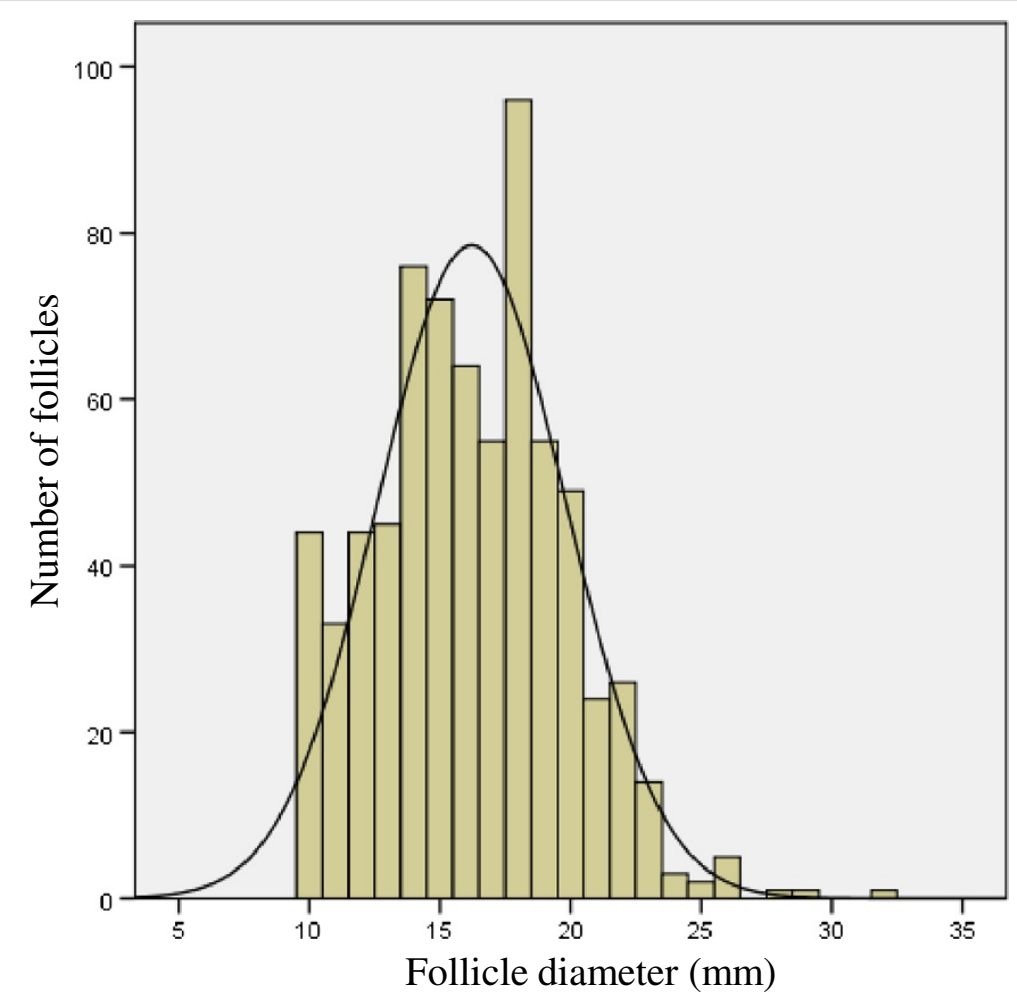

Figure 2 The distribution of follicle diameters in patients with normal serum progesterone $(<1 \mathrm{ng} / \mathrm{ml})$. 
Table 2 The influence of delaying oocyte maturation in patients with a normal progesterone level on the yield of (mature) oocytes, fertilised oocytes and good quality embryos

\begin{tabular}{|c|c|c|c|c|c|}
\hline Day hCG & Number included (cycles/[patients]) & Oocytes & MII & $2 \mathrm{PN}$ & GQE \\
\hline 0 (LPE) & $28[20]$ & $9.36(3.21)$ & $7.64(3.26)$ & $5.29(3.26)$ & $4.32(2.62)$ \\
\hline \multirow[t]{4}{*}{$+1(\mathrm{LPL})$} & $31[31]$ & $12.58(7.62)$ & $10.29(6.35)$ & $7.48(5.25)$ & $5.74(4.61)$ \\
\hline & Mean difference & 2.97 & 2.41 & 1.80 & 1.18 \\
\hline & $95 \% \mathrm{Cl}$ & 0.45 to 5.49 & 0.22 to 4.61 & -0.15 to 3.76 & -0.53 to 2.88 \\
\hline & $P$ & 0.021 & 0.031 & 0.071 & 0.18 \\
\hline
\end{tabular}

Numbers are expressed as means (SD).

Adjusted for age.

U-test was used. To account for correlations between measurements for women with repeated cycles, all further analyses were based on linear and logistic marginal regression models that were fitted using generalised estimating equations with exchangeable working correlations. Although adjustment for baseline covariates was not required in view of the randomised study design, adjustments for age, PCOS and female pathology were used to improve precision in some of the linear models. All tests were performed at the 5\% significance level. Statistical analyses were performed using SPSS, version 21, and R Studio, version 0.97.320.

Subsequent to ending the trial, additional evidence came to suggest that serum progesterone levels $>1.5 \mathrm{ng} /$ $\mathrm{ml}$ at the moment of triggering oocyte maturation might lower pregnancy rates. Therefore, we performed an additional comparison of 2 subgroups of patients: those with low progesterone levels $(<1.0 \mathrm{ng} / \mathrm{ml}$; group A) and those with highly elevated levels ( $>1.5 \mathrm{ng} / \mathrm{ml}$; group B). Fisher's exact test and Student's t-test were again used as described above.

\section{Results}

Seventy-two patients with at least three follicles $\geq 18 \mathrm{~mm}$ had serum progesterone levels $>1 \mathrm{ng} / \mathrm{ml}$. They were randomised into 2 groups (HPE and HPL) of 36 individuals each. In the HPE group, the oocyte maturation trigger was administered on the same day. In the HPL group, hCG was injected 24 hours later. In the remaining cases with low serum progesterone levels
(<1 ng/ml), 59 patients had 30 to $50 \%$ of their follicles measuring equal to or greater than $18 \mathrm{~mm}$. After randomisation, 28 patients were allocated to the LPE group and received hCG on the same day. The remaining 31 patients (LPL group) were triggered 24 hours later. All eligible patients were randomised and could be allocated (Figure 1). The data were analysed after correcting for duplicate patients in each group.

No important differences were observed between the LPE and LPL groups and between the HPE and HPL groups for all controlled variables (Table 1): age of the female, gravidity, parity, duration of infertility, ovarian reserve determined by $\mathrm{AMH}$, peak estradiol level, number of transferred embryos, diagnostic criteria (such as female pathology, endometriosis, ovarian dysfunction and PCOS), male pathology, stimulation protocol, number of cancellations, number of failed fertilisations and the experience of the physician performing the embryo transfer.

What is the effect of delaying the oocyte maturation trigger by 24 hours in patients with low serum progesterone $(<1 \mathrm{ng} / \mathrm{ml})$ ?

In Figure 2, the distribution of the follicle diameters in these patients is illustrated. By waiting 24 hours (LPL group), we obtained more oocytes and predominantly more mature ones compared with the LPE group, where hCG was administered on the same day (Table 2). Multivariate analysis with correction for the female's age showed a

Table 3 The influence of delaying oocyte maturation in patients with a normal progesterone level on pregnancy and pregnancy outcome

\begin{tabular}{lcccccccc}
\hline Day hCG & PR/cycle & CPR/cycle & OPR/cycle & LBR/cycle & & CIR/E* & OIR/E* & LBR/E* \\
\hline O (LPE) & $31.3 \%$ & $31.3 \%$ & $27.1 \%$ & $27.1 \%$ & & $0.27(0.42)$ & $0.22(0.40)$ & $0.22(0.40)$ \\
+1 (LPL) & $35.5 \%$ & $29.0 \%$ & $25.8 \%$ & $25.8 \%$ & & $0.26(0.43)$ & $0.24(0.43)$ & $0.24(0.43)$ \\
Odds ratio & 1.24 & 0.92 & 1.00 & 1.00 & Mean difference & -0.017 & 0.017 & 0.017 \\
$95 \%$ Cl & 0.40 to 3.86 & 0.29 to 2.92 & 0.30 to 3.37 & 0.30 to 3.37 & $95 \% \mathrm{Cl}$ & -0.23 to 0.20 & -0.20 to 0.23 & -0.20 to 0.23 \\
$P$ & 0.71 & 0.88 & 1.00 & 1.00 & $P$ & 0.88 & 0.87 & 0.87 \\
\hline
\end{tabular}

*Numbers are expressed as means (SD).

Unadjusted. 


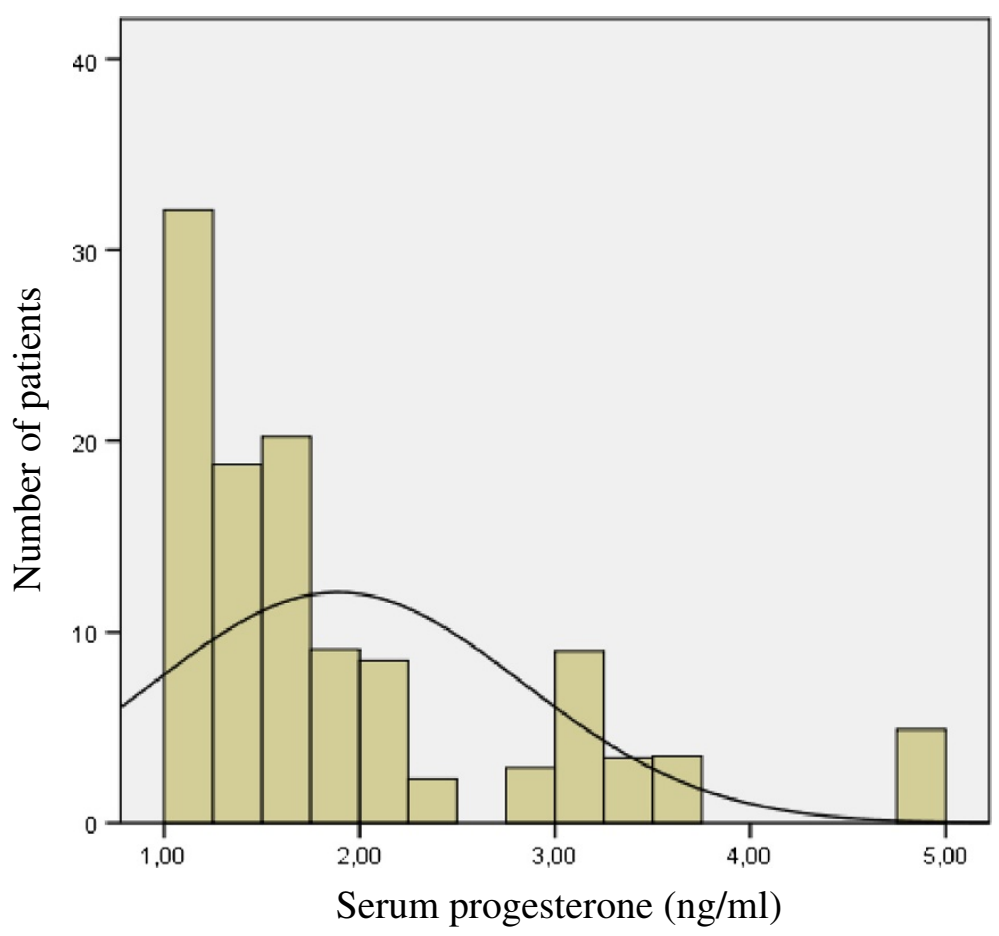

Figure 3 The distribution of progesterone levels in patients with elevated serum progesterone (>1 ng/ml).

significant difference in the number of oocytes $(\mathrm{p}=0.021)$ and in the number of mature oocytes $(\mathrm{p}=0.031)$ in favour of the LPL group (Table 2). No statistically significant differences were found in the number of fertilised oocytes and the number of good-quality embryos.

Several secondary variables were evaluated to compare the pregnancy rates and pregnancy outcomes. No significant differences were found between groups LPE and LPL (Table 3). Multivariate analysis did not influence the final results.

What is the effect of delaying the oocyte maturation trigger by 24 hours in patients with high serum progesterone (>1 $\mathrm{ng} / \mathrm{ml})$ ?

Figure 3 reveals a non-normal distribution of elevated progesterone levels. Thirty patients (48 cycles) had moderately elevated serum progesterone levels $(>1 \mathrm{ng} / \mathrm{ml}$ and $\leq 1.5 \mathrm{ng} / \mathrm{ml}$ ). Levels higher than $1.5 \mathrm{ng} / \mathrm{ml}$ were found in 23 patients ( 24 cycles). Cases with very high progesterone levels ( $>3 \mathrm{ng} / \mathrm{ml}$ ) were very scarce (3 patients).

The yield of mature oocytes was not different between the HPE (hCG administered the same day) and HPL (hCG administered 24 hours later) groups. Multivariate analysis did not affect the results (Table 4). The other variables (viz., number of oocytes recovered, fertilised oocytes, good quality embryos and all variables describing implantation and pregnancy rate) were also comparable (Table 5).

\section{What is the effect of highly elevated serum progesterone $(>1.5 \mathrm{ng} / \mathrm{ml})$ ?}

We also compared the findings between patients with low progesterone levels (group A) and patients with very high progesterone levels (>1.5 ng/ml) (group B) who were

Table 4 The influence of delaying oocyte maturation in patients with an elevated progesterone level on the yield of (mature) oocytes, fertilised oocytes and good quality embryos

\begin{tabular}{lccccc}
\hline Day hCG & Number included (cycles/[patients]) & Oocytes & MII & 2PN & GQE \\
\hline $0(\mathrm{HPE})$ & $36[28]$ & $14.23(8.44)$ & $12.03(7.09)$ & $8.22(5.84)$ & $6.5(5.02)$ \\
$+1(\mathrm{HPL})$ & $36[25]$ & $13.06(10.00)$ & $11.81(9.91)$ & $7.78(5.86)$ & -0.97 \\
& Mean difference & -1.52 & -0.44 & $-3.2(4.80)$ \\
& $95 \% \mathrm{Cl}$ & -5.30 to 2.27 & -3.65 to 2.78 & -3.49 to 1.55 & -2.98 to 1.48 \\
& $\mathrm{P}$ & 0.43 & 0.79 & 0.45 & 0.51 \\
\hline
\end{tabular}

Numbers are expressed as numbers or as mean (SD).

Adjusted for PCO and female pathology. 
Table 5 The influence of delaying oocyte maturation in patients with an elevated progesterone level on pregnancy and pregnancy outcome

\begin{tabular}{lcccccccc}
\hline Day hCG & PR/cycle & CPR/cycle & OPR/cycle & LBR/cycle & & CIR/E* & OIR/E* & LBR/E* \\
\hline O (HPE) & $20.7 \%$ & $20.1 \%$ & $17.6 \%$ & $17.6 \%$ & & $0.16(0.33)$ & $0.15(0.33)$ & $0.15(0.33)$ \\
+1 (HPL) & $31.8 \%$ & $28.8 \%$ & $23.2 \%$ & $23.2 \%$ & & $0.23(0.38)$ & $0.18(0.36)$ & $0.18(0.36)$ \\
Odds ratio & 1.75 & 1.61 & 1.41 & 1.41 & Mean difference & 0.063 & 0.033 & 0.033 \\
$95 \% \mathrm{Cl}$ & 0.59 to 5.22 & 0.54 to 4.78 & 0.46 to 4.34 & 0.46 to 4.34 & $95 \% \mathrm{Cl}$ & -0.10 to 0.22 & -0.12 to 0.18 & -0.12 to 0.18 \\
$\mathrm{P}$ & 0.31 & 0.39 & 0.55 & 0.55 & $\mathrm{P}$ & 0.44 & 0.67 & 0.67 \\
\hline
\end{tabular}

*Numbers are expressed as means (SD).

Unadjusted.

triggered on the day of the final monitoring (i.e., no delay of 24 hours). The numbers of (mature) oocytes, fertilised oocytes and good quality embryos were all significantly higher in group $\mathrm{B}$. The variables describing implantation and pregnancy outcome were lower in group B, although statistical significance was lacking. More data are required to confirm our findings (Table 6).

\section{Discussion}

The effect of increasing progesterone levels

Increasing serum progesterone during stimulation for IVF/ICSI may have a negative impact on pregnancy rates. Venetis [10] reviewed this phenomenon and included studies with progesterone levels $\geq 0.9 \mathrm{ng} / \mathrm{ml}$. Initially, this effect was described in only a fraction of the reports. In a recent systemic review [11], he expanded and further confirmed his findings. It seemed that a ratio

Table 6 The oocyte yield and pregnancy outcome in subgroups categorized by highly different progesterone levels

\begin{tabular}{lccc}
\hline & $\begin{array}{c}\text { Group A } \\
\text { Prog } \leq \mathbf{1} \\
\mathbf{n g} / \mathbf{m l} \text { D0 }\end{array}$ & $\begin{array}{c}\text { Group B } \\
\text { Prog > 1,5 } \\
\mathbf{n g} / \mathbf{m l ~ D 0}\end{array}$ & P \\
\hline Number of patients included & 28 & 14 & \\
Number of oocytes & $9,36(3,21)^{*}$ & $16,71(9,93)^{*}$ & 0.02 \\
Number of mature oocytes & $7,64(3,26)^{*}$ & $13,43(8,36)^{*}$ & 0.03 \\
Number of fertilised oocytes & $5,29(3,26)^{*}$ & $10,00(6,50)^{*}$ & 0.02 \\
Number of good quality embryos & $4,32(2,62)^{*}$ & $7,93(5,14)^{*}$ & 0.03 \\
PR/cycle & $31.3 \%$ & $7,14 \%$ & 0.07 \\
CPR/cycle & $31.3 \%$ & $7,14 \%$ & 0.07 \\
OPR/cycle & $27.1 \%$ & $7,14 \%$ & 0.11 \\
LBR/cycle & $27.1 \%$ & $7,14 \%$ & 0.11 \\
CIR/embryo & $0.27(0.42)$ & $0.07(0.27)$ & 0.07 \\
OIR/embryo & $0.22(0.40)$ & $0.07(0.27)$ & 0.16 \\
LBR/embryo & $0.22(0.40)$ & $0.07(0.27)$ & 0.16 \\
\hline
\end{tabular}

Numbers are expressed as numbers or as means (SD) unless explained differently. ${ }^{*} p<0.05$. of progesterone-to-estradiol $>0.48$ reduced pregnancy rates in antagonist cycles and that this ratio was found to be an independent predictor of pregnancy [12]. The effect of elevated progesterone levels was higher in patients with a rather low ovarian response [11]. An emerging progesterone increase could be predicted by the number of follicles and an increase in serum estradiol [13]. This possible negative effect was the consequence of endometrial changes, because it was not described in oocyte donation programs [14] or when embryos that were obtained in a cycle with high progesterone were cryopreserved and subsequently thawed and transferred [15]. Van Vaerenbergh [16] demonstrated that gene expression in the endometrium thoroughly changed when serum progesterone levels were higher than $1.5 \mathrm{ng} / \mathrm{ml}$. This threshold of $1.5 \mathrm{ng} / \mathrm{ml}$ was further used by Bosch [6], who clearly demonstrated a negative effect on pregnancy rates in both agonist and antagonist cycles. Although our study was not powered to compare implantation and pregnancy rates, the additional data in Table 6 confirmed these findings.

The yield of mature oocytes was either not mentioned or only calculated as a secondary variable in most studies. Mio [17], Bustillo [18] and Venetis [11] demonstrated a higher number of retrieved oocytes in cycles with elevated progesterone levels. The cut off values for positive progesterone levels differed between studies, and uniform conclusions were not formulated. In our own study (Table 4), there was no significant difference in the number of (mature) oocytes.

From these observations, we may conclude that there is no evidence that increasing progesterone levels have a negative effect in cases where eggs are recruited for donation or for further cryopreservation, be it for medical or non-medical reasons.

Another possibility is that, if rising progesterone levels are encountered during the stimulation procedure, we can delay for a few days more to yield a maximum number of good-quality eggs. They can be fertilised and cryopreserved and be used for transfer later on, the so-called "segmented procedure" [19]. 


\section{The importance of follicle diameters}

The ultrasound criteria to decide the best moment for triggering oocyte maturation have always been a point of discussion.

When no GnRH agonist/antagonist has been used, a leading follicle diameter of $16 \mathrm{~mm}$ or more and a serum estradiol of at least $600 \mathrm{pg} / \mathrm{ml}$ have served as guidelines for administering 10000 IU hCG [20]. Using a GnRH agonist-either in a long or short protocol-multiple criteria have been suggested. This can be explained by the different stimulation protocols that have been used and the variations in study designs. The leading follicles have had to reach diameters of 16 to $20 \mathrm{~mm}$ in most cases [1,2,21-28].

In antagonist cycles, most studies have proposed leading follicle diameters of 16 to $17 \mathrm{~mm}$ [4,9,29-31]. It seems that, in cycles where an antagonist has been used, the decision has been made somewhat earlier than in agonist cycles. In 2006, the Brussels GnRH antagonist Consensus Workshop Group stated that the optimal timing for triggering oocyte maturation when using a $\mathrm{GnRH}$ antagonist protocol needed to be explored further [32].

In our study, we focused on follicle diameters in selected patients with low progesterone levels $(<1 \mathrm{ng} / \mathrm{ml})$. They all reached the threshold of having a least 3 follicles $\geq 18 \mathrm{~mm}$ [5] with $30-50 \%$ of them being large enough. When waiting 24 hours to inject hCG, a larger number of (mature) oocytes were obtained (Table 2), as has already been mentioned by others [27].

In our series, we could not confirm a higher pregnancy rate in the group in which we triggered oocyte maturation 1 day later (Table 3). This confirms the findings by Tremmelen and Lane [33], who found that advancing or delaying hCG administration by 1 day from 'ideal' had no adverse impact on IVF treatment outcomes in nonprogrammed GnRH antagonist cycles. Again, we must notice that our study was not powered to compare pregnancy rates, so conclusions on cycle outcomes must be interpreted with caution.

In spite of this, our findings support the idea that a higher yield of mature oocytes indirectly contributes to a higher overall productivity rate, as mentioned by Stanger and Yovich [34].

\section{Conclusions}

As soon as three follicles have a diameter $\geq 18 \mathrm{~mm}$, further decisions to pinpoint the moment for administering $\mathrm{hCG}$ depend on the progesterone level. If the progesterone level is higher than $1 \mathrm{ng} / \mathrm{ml}$, delaying the administration of hCG by 24 hours has no effect on the number of mature oocytes. If the progesterone level is $\leq 1 \mathrm{ng} / \mathrm{ml}$ and $30-50 \%$ of the follicles have diameters $\geq 18 \mathrm{~mm}$, delaying oocyte maturation by 24 hours is advised.

\section{Abbreviations}

2PN: 2 pro-nuclear; AMH: Anti-Müllerian hormone; CIR: Clinical implantation rate; CPR: Clinical pregnancy rate; $\mathrm{GnRH}$ : Gonadotrophin releasing hormone; GQE: Good quality embryos; hCG: Human chorionic gonadotrophin: HPE: High progesterone early group; HPL: High progesterone late group; LBR: Live birth rate; LH: Luteinizing hormone; LPE: Low progesterone early group; LPL: Low progesterone late group; MIl: Metaphase 2 oocytes; OIR: Ongoing implantation rate; OPR: Ongoing pregnancy rate;

PCOS: Polycystic ovary syndrome; PR: Pregnancy rate; SD: Standard deviation.

\section{Competing interests}

The authors declare that they have no competing interests.

\section{Authors' contributions}

FV designed the study protocol, included patients, analysed the data and wrote the manuscript. JG included patients and helped in analysing the data. SV performed the statistical analysis. AD included patients and helped in putting the data into the database. KT helped in structuring the database. PD included patients and all authors critically revised the article and approved it to be published.

\section{Acknowledgements}

$\mathrm{PD}$ is holder of a clinical research mandate by the Flemish Foundation for Scientific Research (FWO-Vlaanderen)

\section{Author details}

${ }^{1}$ Centre for Reproductive Medicine, University Hospital Ghent, De Pintelaan 185, Gent 9000, Belgium. '2Department of Applied Mathematics, Computer Science and Statistics, Ghent University, Krijgslaan 281 S9, Gent 9000, Belgium.

Received: 1 February 2014 Accepted: 17 April 2014

Published: 23 April 2014

\section{References}

1. Ectors FJ, Vanderzwalmen P, VanHoeck J, Nijs M, Verhaegen G, Delvigne A, Schoysman R, Leroy F: Relationship of human follicular diameter with oocyte fertilization and development after in-vitro fertilization or intracytoplasmic sperm injection. Hum Reprod 1997, 12:2002-2005.

2. Inaudi P, Germond M, Senn A, Degrandi P: Timing of Hcg administration in cycles stimulated for in-vitro fertilization - specific impact of heterogeneous follicle sizes and steroid concentrations in plasma and follicle fluid on decision procedures. Gynecol Endocrinol 1995, 9:201-208.

3. Kwan I, Bhattacharya S, McNeil A, Van Rumste MME: Monitoring of stimulated cycles in assisted reproduction IVF and ICSI. Cochrane Database Syst Rev 2008 [http://onlinelibrary.wiley.com/doi/10.1002/14651858.CD005289.pub2/ abstract].

4. Kyrou D, Kolibianakis EM, Fatemi HM, Tarlatzis BC, Tournaye H, Devroey P: Is earlier administration of human chorionic gonadotrophin (hCG) associated with the probability of pregnancy in cycles stimulated with recombinant follicle-stimulating hormone and gonadotrophin-releasing hormone $(\mathrm{GnRH})$ antagonists? A prospective randomized trial. Fertil Steril 2011, 96:1112-1115.

5. Garcia-Velasco JA, Isaza V, Vidal C, Landazabal A, Remohi J, Simon C, Pellicer A: Human ovarian steroid secretion in vivo: effects of $\mathrm{GnRH}$ agonist versus antagonist (cetrorelix). Hum Reprod 2001, 16:2533-2539.

6. Bosch E, Labarta E, Crespo J, Simon C, Remohi J, Jenkins J, Pellicer A: Circulating progesterone levels and ongoing pregnancy rates in controlled ovarian stimulation cycles for in vitro fertilization: analysis of over 4000 cycles. Hum Reprod 2010, 25:2092-2100.

7. Dirckx K, Cabri P, Merien A, Galajdova L, Gerris J, Dhont M, De Sutter P: Does low-dose aspirin improve pregnancy rate in IVF/ICSI? A randomized double-blind placebo controlled trial. Hum Reprod 2009, 24:856-860.

8. Zegers-Hochschild F, Adamson GD, De Mouzon J, Ishihara O, Mansour R, Nygren K, Sullivan E, van der Poel S: International Committee for Monitoring Assisted Reproductive T, World Health O: The International Committee for Monitoring Assisted Reproductive Technology (ICMART) and the World Health Organization (WHO) Revised Glossary on ART Terminology, 2009. Hum Reprod 2009, 24:2683-2687.

9. Kolibianakis EM, Bourgain C, Papanikolaou EG, Camus M, Tournaye H, Van Steirteghem AC, Devroey P: Prolongation of follicular phase by delaying 
hCG administration results in a higher incidence of endometrial advancement on the day of oocyte retrieval in GnRH antagonist cycles. Hum Reprod 2005, 20:2453-2456.

10. Venetis CA, Kolibianakis EM, Papanikolaou E, Bontis J, Devroey P, Tarlatzis BC Is progesterone elevation on the day of human chorionic gonadotrophin administration associated with the probability of pregnancy in in vitro fertilization? A systematic review and meta-analysis. Hum Reprod Update 2007, 13:343-355.

11. Venetis CA, Kolibianakis EM, Bosdou JK, Tarlatzis BC: Progesterone elevation and probability of pregnancy after IVF: a systematic review and meta-analysis of over 60000 cycles. Hum Reprod Update 2013 19:433-457.

12. Cetinkaya ES, Berker B, Aytac R, Atabekoglu C, Sonmezer M, Ozmen B: The value of the progesterone-to-estradiol ratio on the day of hCG administration in predicting ongoing pregnancy and live birth rates in normoresponders undergoing GnRH antagonist cycles. Eur J Obstet Gynecol Reprod Biol 2013, 170:452-457.

13. Kyrou D, Al-Azemi M, Papanikolaou EG, Donoso P, Tziomalos K, Devroey P, Fatemi HM: The relationship of premature progesterone rise with serum estradiol levels and number of follicles in GnRH antagonist/recombinant FSH-stimulated cycles. Eur J Obstet Gynecol Reprod Biol 2012, 162:165-168.

14. Al-Azemi M, Kyrou D, Kolibianakis EM, Humaidan P, Van Vaerenbergh I, Devroey P, Fatemi HM: Elevated progesterone during ovarian stimulation for IVF. Reprod Biomed Online 2012, 24:381-388.

15. Silverberg KM, Martin M, Olive DL, Burns WN, Schenken RS: Elevated serum progesterone levels on the day of human chorionic-gonadotrophin administration in in-vitro fertilization cycles do not adversely affect embryo quality. Fertil Steril 1994, 61:508-513.

16. Van Vaerenbergh I, Fatemi HM, Blockeel C, Van Lommel L, In't Veld P, Schuit F, Kolibianakis EM, Devroey P, Bourgain C: Progesterone rise on HCG day in $\mathrm{GnRH}$ antagonist/rFSH stimulated cycles affects endometrial gene expression. Reprod Biomed Online 2011, 22:263-271.

17. Mio Y, Sekijima A, Iwabe T, Onohara Y, Harada T, Terakawa N: Subtle rise in serum progesterone during the follicular phase as a predictor of the outcome of invitro fertilization. Fertil Steril 1992, 58:159-166.

18. Bustillo M, Stern JJ, Coulam CB: Serum progesterone at the time of human chorionic gonadotrophin does not predict pregnancy in in-vitro fertilization and embryo transfer. Hum Reprod 1995, 10:2862-2867.

19. Fatemi HM, Blockeel C, Devroey P: Ovarian stimulation: today and tomorrow. Curr Pharm Biotechnol 2012, 13:392-397.

20. Murad NM: Ultrasound or ultrasound and hormonal determinations for in vitro fertilization monitoring. Int J Gynaecol Obstet 1998, 63:271-276.

21. De Sutter P, Dhont M: Poor response after hormonal stimulation for in vitro fertilization is not related to ovarian aging. Fertil Steril 2003, 79:1294-1298.

22. Elgindy EA: Progesterone level and progesterone/estradiol ratio on the day of hCG administration: detrimental cutoff levels and new treatment strategy. Fertil Steril 2011, 95:1639-1644.

23. Golan A, Herman A, Soffer Y, Bukovsky I, Ronel R: Ultrasonic control without hormone determination for ovulation induction in in-vitro fertilization-embryo transfer with gonadotrophin-releasing-hormone analog and human menopausal gonadotrophin. Hum Reprod 1994, 9:1631-1633.

24. Kovacs P, Kovats T, Bernard A, Zadori J, Szmatona G, Kaali SG: Comparison of serum and follicular fluid hormone levels with recombinant and urinary human chorionic gonadotrophin during in vitro fertilization. Fertil Steril 2008, 90:2133-2137.

25. Lass A: Group UKToh: Monitoring of in vitro fertilization-embryo transfer cycles by ultrasound versus by ultrasound and hormonal levels: a prospective, multicenter, randomized study. Fertil Steril 2003, 80:80-85.

26. Miller KF, Goldberg JM, Falcone T: Follicle size and implantation of embryos from in vitro fertilization. Obstet Gynecol 1996, 88:583-586.

27. Mochtar MH, Custers IM, Koks CAM, Bernardus RE, Verhoeve HR, Mol BW, Van Wely M, van der Veen F: Timing oocyte collection in GnRH agonists down-regulated IVF and ICSI cycles: a randomized clinical trial. Hum Reprod 2011, 26:1091-1096.

28. Tan SL, Balen A, El Hussein E, Mills C, Campbell S, Yovich J, Jacobs HS: A prospective randomized study of the optimum timing of human chorionic gonadotrophin administration after pituitary desensitization in in vitro fertilization. Fertil Steril 1992, 57:1259-1264.
29. Hauzman EE, Bodri D, Guillen JJ, Vidal R, Coll O, Vernaeve V: Exploring different criteria by 2D or 3D ultrasound for triggering final oocyte maturation in an oocyte donation program: a randomized pilot study. Hum Reprod 2011, 26:195-196.

30. Kolibianakis EM, Albano C, Camus M, Tournaye H, Van Steirteghem AC, Devroey P: Prolongation of the follicular phase in in vitro fertilization results in a lower ongoing pregnancy rate in cycles stimulated with recombinant follicle-stimulating hormone and gonadotrophin-releasing hormone antagonists. Fertil Steril 2004, 82:102-107.

31. Kolibianakis EM, Papanikolaou EG, Tournaye H, Camus M, Van Steirteghem AC, Devroey P: Triggering final oocyte maturation using different doses of human chorionic gonadotrophin: a randomized pilot study in patients with polycystic ovary syndrome treated with gonadotrophin-releasing hormone antagonists and recombinant follicle-stimulating hormone. Fertil Steril 2007, 88:1382-1388.

32. Tarlatzis BC, Fauser BC, Kolibianakis EM, Diedrich K, Devroey P: GnRH antagonists in ovarian stimulation for IVF. Hum Reprod Update 2006, 12:333-340.

33. Tremellen KP, Lane M: Avoidance of weekend oocyte retrievals during $\mathrm{GnRH}$ antagonist treatment by simple advancement or delay of hCG administration does not adversely affect IVF live birth outcomes. Hum Reprod 2010, 25:1219-1224.

34. Stanger JD, Yovich JL: Follicle recruitment determines IVF productivity rate via the number of embryos frozen and subsequent transfers. Reprod Biomed Online 2013, 27:286-296.

doi:10.1186/1477-7827-12-31

Cite this article as: Vandekerckhove et al.: Delaying the oocyte maturation trigger by one day leads to a higher metaphase II oocyte yield in IVF/ICSI: a randomised controlled trial. Reproductive Biology and Endocrinology 2014 12:31.

\section{Submit your next manuscript to BioMed Central and take full advantage of:}

- Convenient online submission

- Thorough peer review

- No space constraints or color figure charges

- Immediate publication on acceptance

- Inclusion in PubMed, CAS, Scopus and Google Scholar

- Research which is freely available for redistribution 